\title{
GRID GENERATION AND HEAT TRANSFER IN A COMPLEX TOPOLOGY MARITIME PINE TREE IN FOREST FIRE ENVIRONMENTS
}

\section{EUSÉBIO Z. CONCEIÇÃO ${ }^{1}$, JOÃO M. GOMES ${ }^{2}$, M $^{\mathrm{a}}$ MANUELA LÚCIO ${ }^{1}$, JORGE N. RAPOSO ${ }^{3}$, DOMINGOS X. VIEGAS ${ }^{3}$ AND $M^{\text {a }}$ TERESA VIEGAS ${ }^{3}$}

\author{
${ }^{1}$ FCT - Universidade do Algarve \\ Campus de Gambelas, 8005-139 Faro, Portugal \\ econcei@ualg.pt; maria.manuela.lucio@gmail.com \\ ${ }^{2}$ CINTAL \\ Campus de Gambelas, 8005-139 Faro, Portugal \\ jgomes@ualg.pt \\ ${ }^{3}$ Universidade de Coimbra \\ Pólo II, Pinhal de Marrocos, 3030-290 Coimbra, Portugal \\ rafahunstman@hotmail.com; xavier.viegas@dem.uc.pt; maria.viegas@dem.uc.pt
}

Key words: Pine Tree, Fire Front, Heat Fluxes, Mesh Generation, Tree Geometry, Numerical Simulation.

\begin{abstract}
This article presents a study on the grid generation and heat transfer in a complex topology maritime pine tree in a forest fire environment. The numerical model of the maritime pine tree thermal behaviour is developed and applied. This numerical model is based on energy balance integral equations for the maritime pine tree elements. These equations are obtained for the heat exchanges by conduction within the maritime pine tree elements, by convection between the external maritime pine tree surfaces and the environment, and by radiation between the external maritime pine tree surfaces and the fire front. The geometry of the virtual maritime pine maritime pine tree was here developed applying mesh generation, which is used to evaluate the view factors. In turn, these view factors are used to calculate the heat exchanges by radiation between the virtual maritime pine tree and the fire front. The virtual maritime pine tree geometry is constituted by 8863 cylindrical elements, which represent their trunks, branches and leaves, and it is divided into four levels. The input data considered in the numerical simulation are the mean flame temperature of $500^{\circ} \mathrm{C}$, the air temperature of $20^{\circ} \mathrm{C}$, the wind speed of $10 \mathrm{~m} / \mathrm{s}$ and the air relative humidity around the pine tree of $50 \%$. The numerical simulation results are the view factors and the evolution of the surface temperature of the maritime pine tree elements obtained in a transient regime. The values of the view factors and the surface temperature of the maritime pine tree elements decrease from the first level, near the ground, to the last level, at the top of the maritime pine tree. The stabilization time of the surface temperatures of the maritime pine tree elements decreases according to the increase of the height to which these elements are located.
\end{abstract}




\section{INTRODUCTION}

Maritime pine tree ("pinus pinaster") is one of the most abundant tree species in Portuguese forests and also one of the species that most burns due to forest fires [1]. The numerical study of the thermal behavior of the maritime pine tree is therefore important because it will allow to know and better understand its performance and later conditions when facing a forest fire. This paper presents a study on the development of the geometry of a virtual pine tree based on mesh generation. From this geometry, the necessary view factors will be determined to calculate the temperature distribution on the surfaces of the constituent elements of the pine tree.

The maritime pine thermal response model is based on thermal and radiative numerical models previously developed and applied in the evaluation of thermal response of vehicles [3], buildings [4], human thermo-physiology [5], etc. The finite elements theory was used on the mesh generation of the geometry of the vehicle, building or human body, implemented in these models. The validation of the building thermal response model was done in Conceição and Lúcio [5], for summer conditions. The validation of the human thermal response model was done in Conceição and Lúcio [6].

The radiative heat exchanges are important in the studies of forest fires to analyze the thermal interaction between the tree and the fire front. The use of mesh generation in the radiative heat exchanges can be seen in the works of Conceição and Lúcio [7] and in Conceição et al. [8]. Additional applications of the thermal response model can be noted in Refs. [9-16], for buildings, and in Refs

As purpose, this w geometry of a virtual in

the outer surface of the

factors will be used

Temperature (MRT)
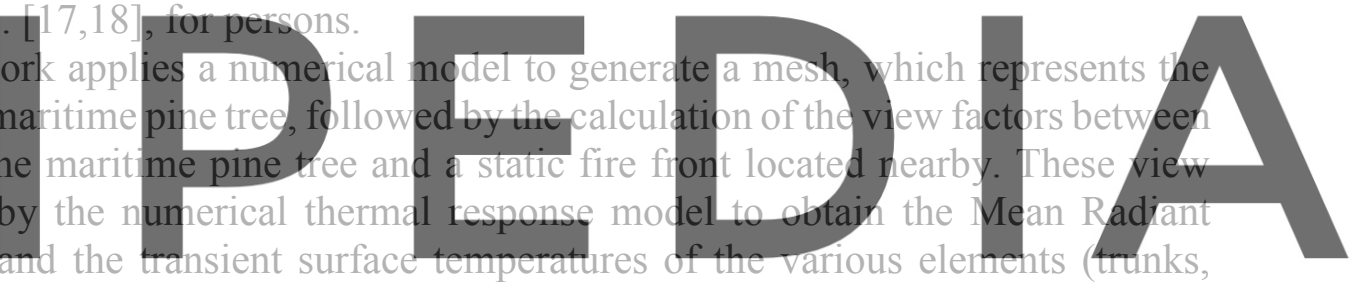

branches and leaves) of the virtual maritime pine tree.

Register for free at https//www.scipedia.com to download the version without the watermark 2 NUMERICAL MODEL

The numerical model is based on mesh generation, which is used to calculate the geometry of the maritime pine tree and the heat exchanges between the fire front and the maritime pine tree.

The definition of the maritime pine tree geometry, namely the main and secondary trunks and branches, is carried out through cylinders. Each cylinder is characterized by the diameter, height, rotation of a beta angle around the $\mathrm{Y}$-axis and rotation of a gamma angle around the Zaxis.

In defining the geometry of the maritime pine tree, two references are considered:

- Global reference x, y, z (see Figure 1a), where all coordinates are defined in the maritime pine tree and in the fire front;

- Particular reference $x$ ', $y^{\prime}, z^{\prime}$, where all coordinates are defined in relation to each of the cylinders.

The fire front also needs to be defined geometrically. In this case, it is a flat surface characterized by height, width, rotation of a beta angle around the $\mathrm{Y}$-axis and rotation of a 
gamma angle around the Z-axis.

In the mesh generation around each of the cylindrical elements of the maritime pine tree, a mesh with $n$ divisions according to angles and $m$ divisions according to length is considered. In the case of the fire plane, a mesh with $p$ divisions according to length and $q$ divisions according to height is considered.

The maritime pine tree thermal response numerical model takes into account the phenomena of radiation, conduction and convection and it is based on energy balance integral equations (equation (1)). These equations are developed for:

- Different cylindrical layers of the main trunks;

- Different cylindrical layers of the secondary trunks;

- Different cylindrical layers of the branches;

- Different cylindrical layers of the leaves.

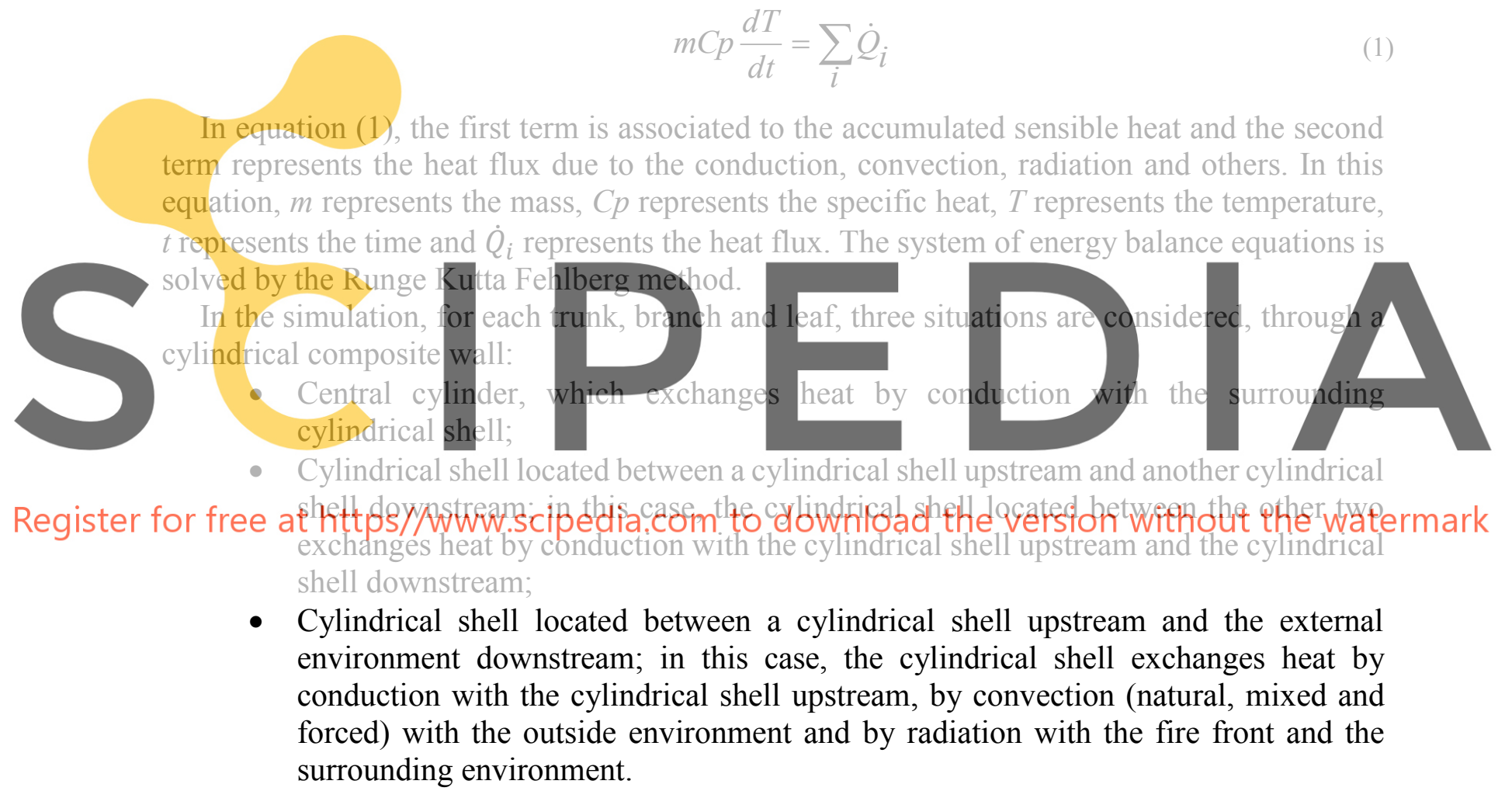

\section{NUMERICAL METHODOLOGY}

The height of the virtual maritime pine tree is $7.5 \mathrm{~m}$. It is constituted by 8863 cylindrical elements divided into 36 trunks, 97 branches and 8730 leaves. These elements are spread over four levels. The first level corresponds to the set of trunks, branches and leaves closest to the ground, while the fourth level corresponds to the set of trunks, branches and leaves located at the top of the maritime pine tree. Each maritime pine tree level is characterized by:

- Eight trunks and one vertical trunk section of the main trunk (Figure 1a);

- Each trunk has three branches, a total of 24 branches; 
- Each branch has ninety leaves distributed by nine levels of ten leaves each (Figure 1b), a total of 2160 leaves;

- One branch and ninety leaves on the top of the higher level.

Table 1 shows the numbering of the elements of the virtual maritime pine tree for each level.

Table 1: Numbering the virtual maritime pine tree elements for each level

\begin{tabular}{ccc}
\hline Level & Trunks/Branches & Leaves \\
\hline 1 & $1-34$ & $134-2293$ \\
\hline 2 & $35-67$ & $2294-4453$ \\
\hline 3 & $68-100$ & $4454-6613$ \\
\hline 4 & $101-133$ & $6614-8863$ \\
\hline
\end{tabular}

The dimensions of the fire front are $10 \mathrm{~m}$ long and $1 \mathrm{~m}$ high. The pine tree is placed perpendicular to the central area of the fire front and at a distance of $5 \mathrm{~m}$ (Figure 2). The fire front is considered static.

The input data of the numerical simulation are as follows: flame mean temperature, $500^{\circ} \mathrm{C}$; air temperature, $20^{\circ} \mathrm{C}$; air relative humidity, $50 \%$; wind speed, $10 \mathrm{~m} / \mathrm{s}$.

The numerical simulation was performed in order to obtain as output data the view factors

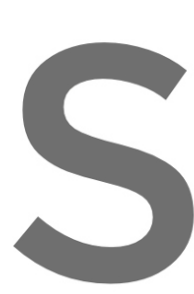
and the evolution of

regime. The eyolution seconds.

Register for free at https//www.scipedia.com to download
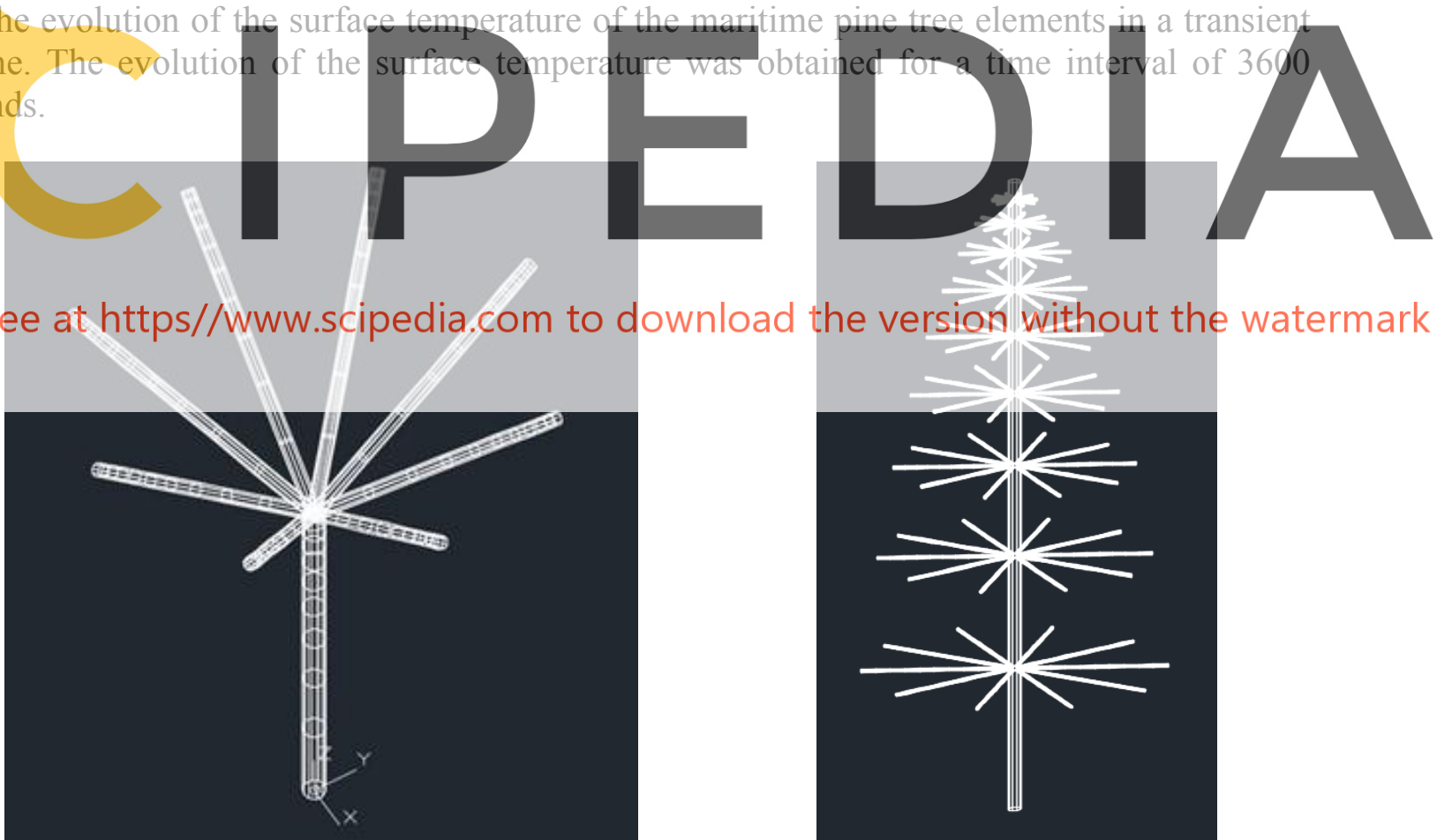

a)

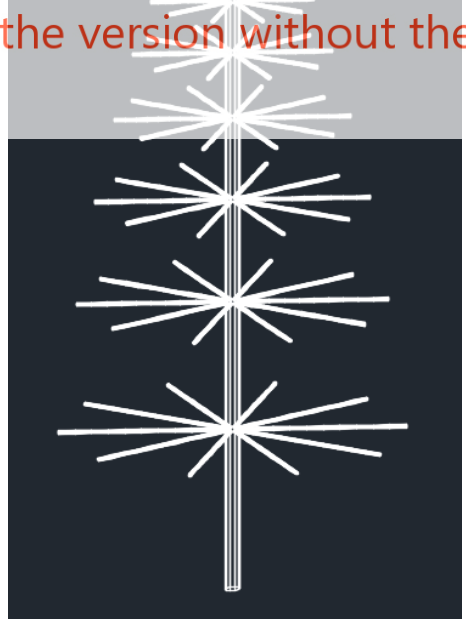

b)

Figure 1: Grid generation: a) between the main trunk and the secondary trunks; b) branch with leaves (pine needles) 


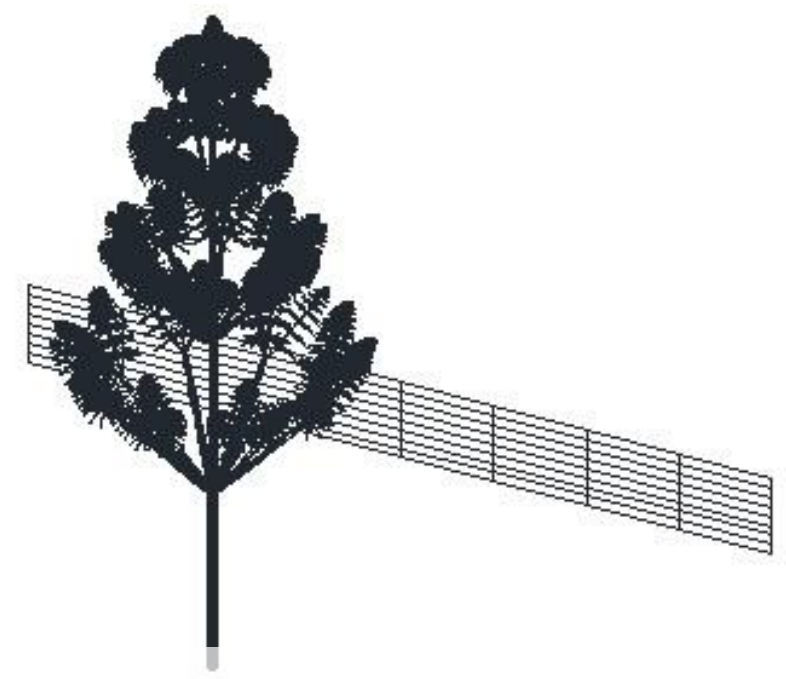

Figure 2: Grid generation on the tree and in the fire front

\section{RESULTS AND DISCUSSION}

In this section, the results obtained from the view factors (Figure 3) and the evolution of the surface temperature (Figures 4 to 7 ) of the maritime pine tree elements are presented and discussed. Figures 4 to 7 are associated, respectively, with levgits 1 to 4 defined in the maritime pine tree. In these Figures, the results abtained in the branches with leaves facing the fire front are presented, that is, those most exposed to the fire. In these Figures, the elements referrin the leaves, the branch to which these leaves are attached and the connected are also numerically identified.
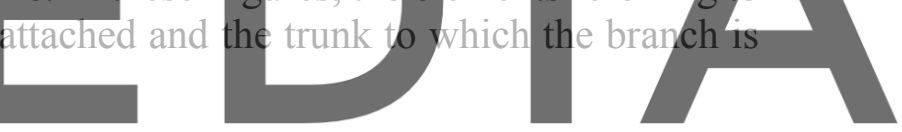

Register for free at https//www.scipedia.com to download the version without the watermark

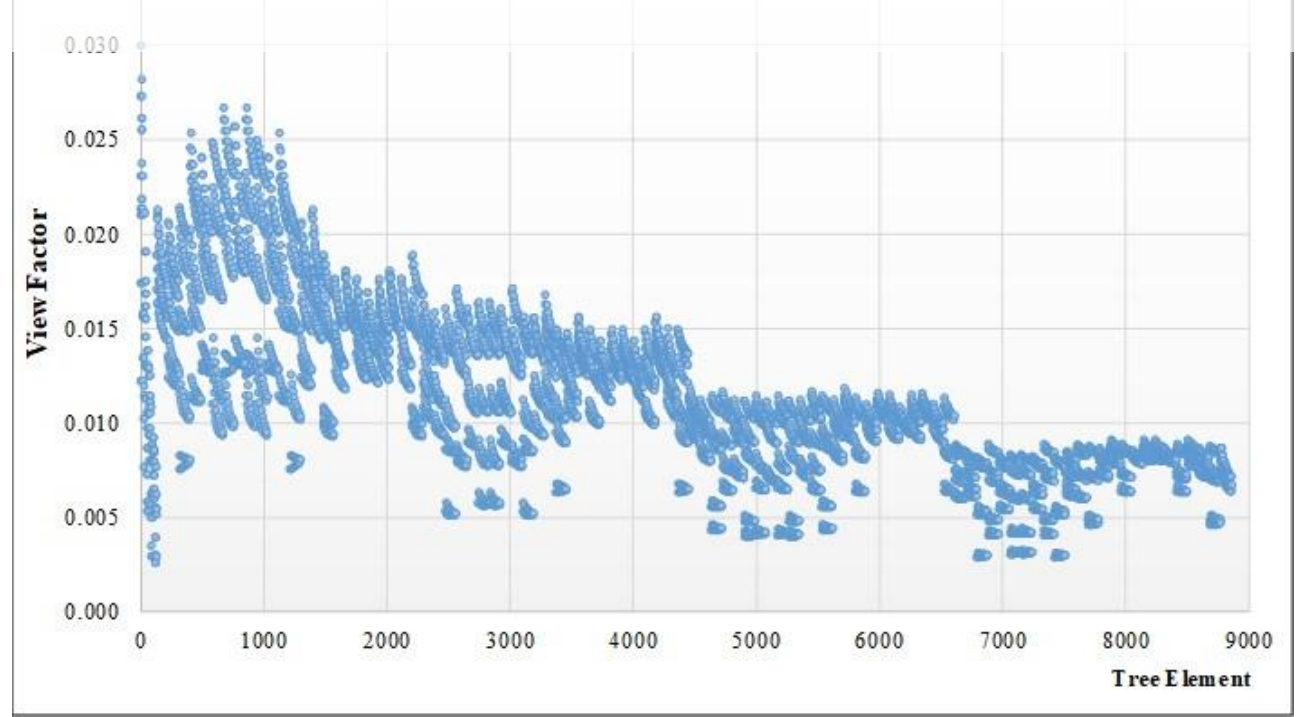

Figure 3: View factors of the maritime pine tree elements 


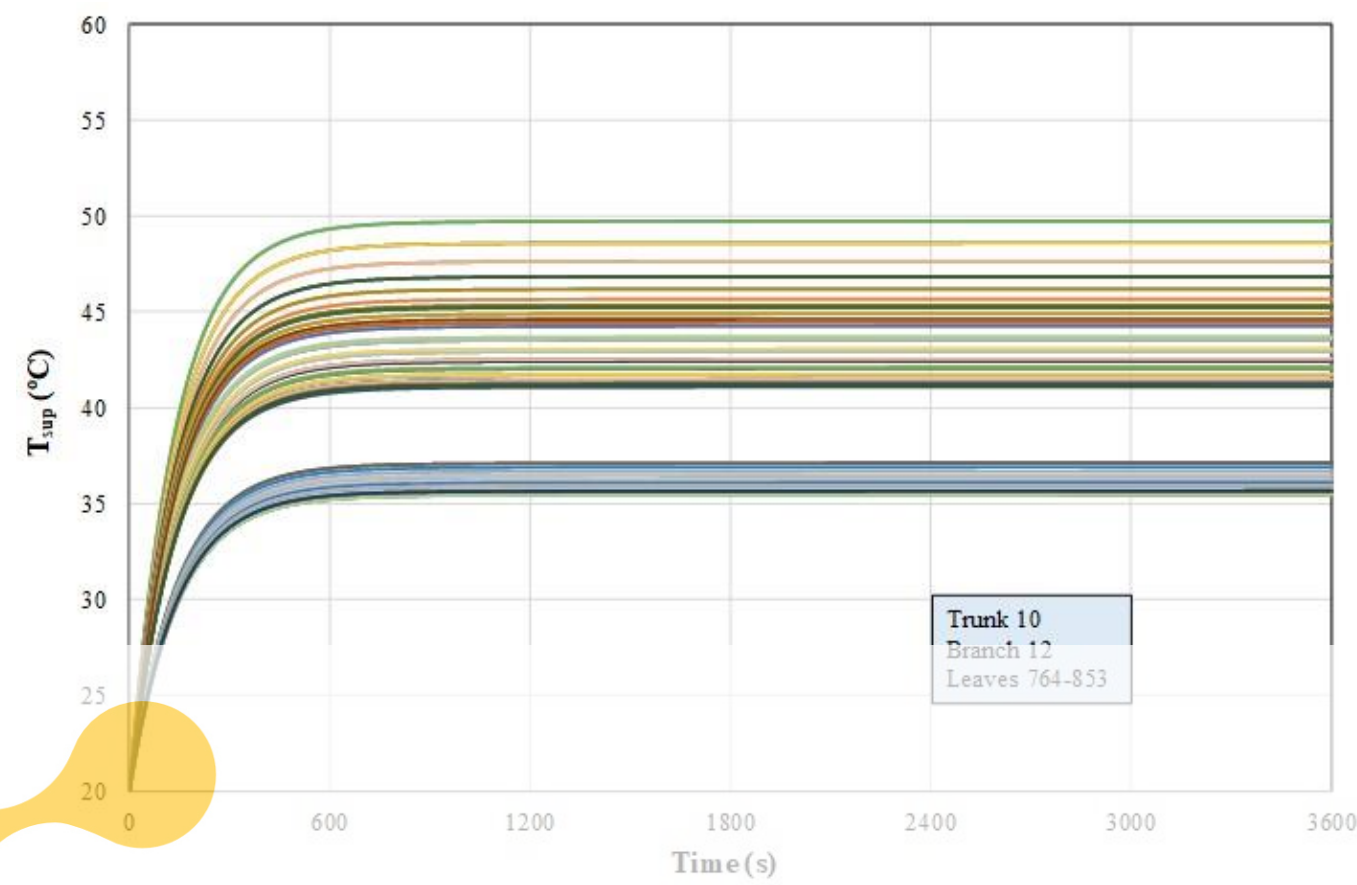

Figure 4: Evolution of the surface temperature of the leaves (elements 764-853) of the branch 12, located on
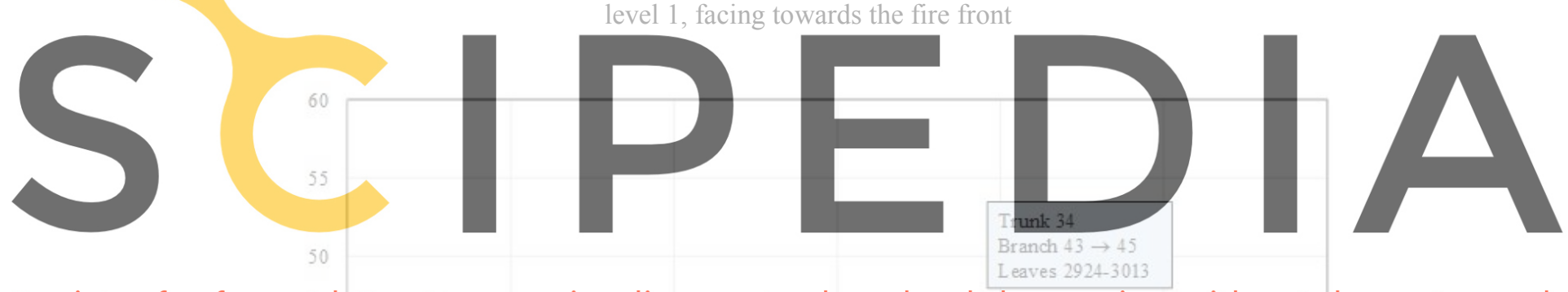

Register for free at https//www.scipedia.com to download the version without the watermark

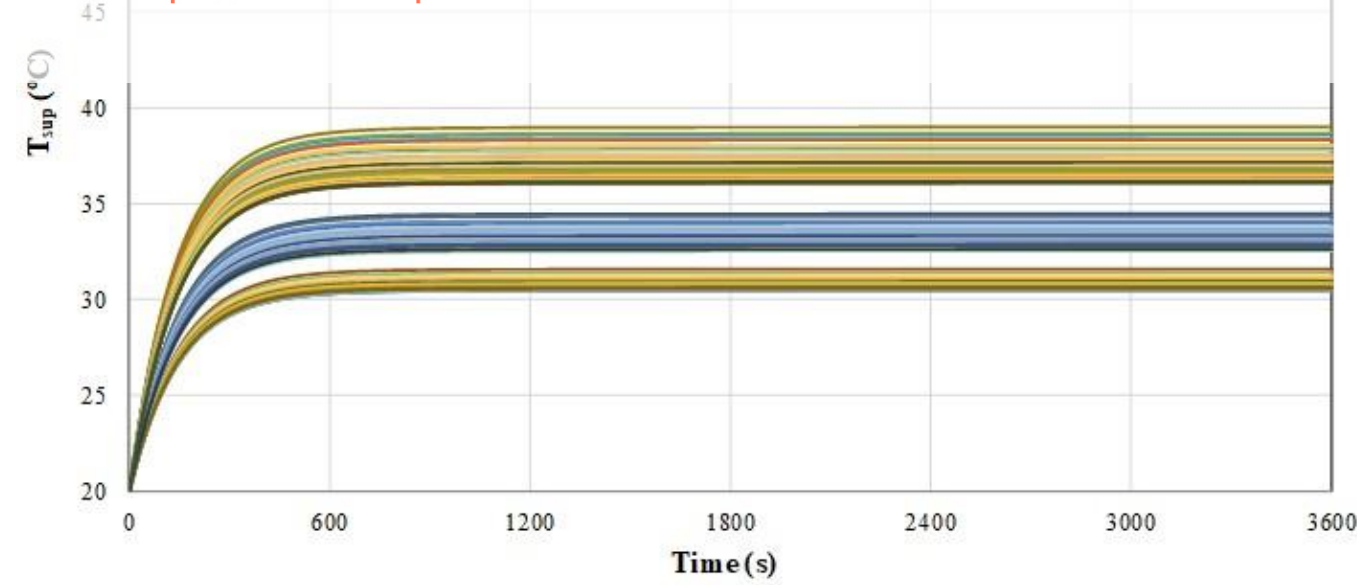

Figure 5: Evolution of the surface temperature of the leaves (elements 2924-3013) of the branch 45, located on level 2, facing towards the fire front 


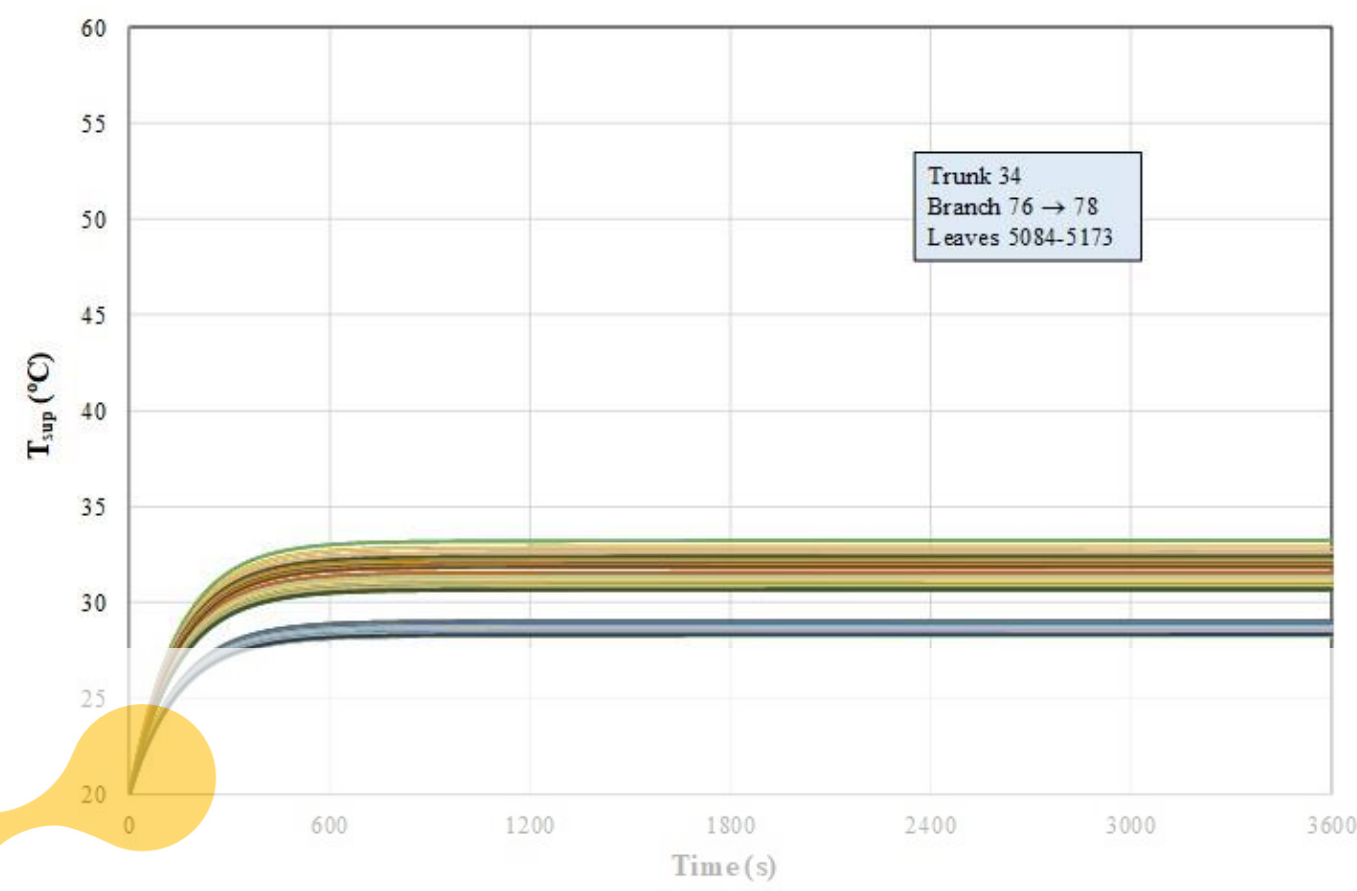

Figure 6: Evolution of the surface temperature of the leaves (elements 5084-5173) of the branch 78, located on
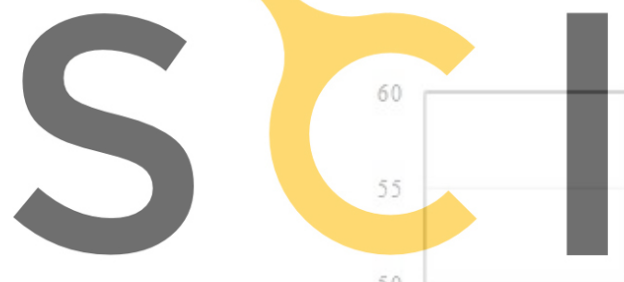
level 3, facing towards the fire front
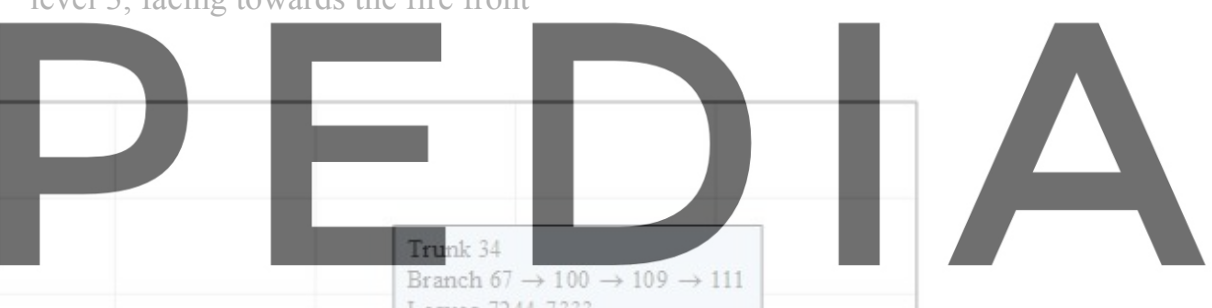

Register for free at https//www.scipedia.com to download the version without the watermark

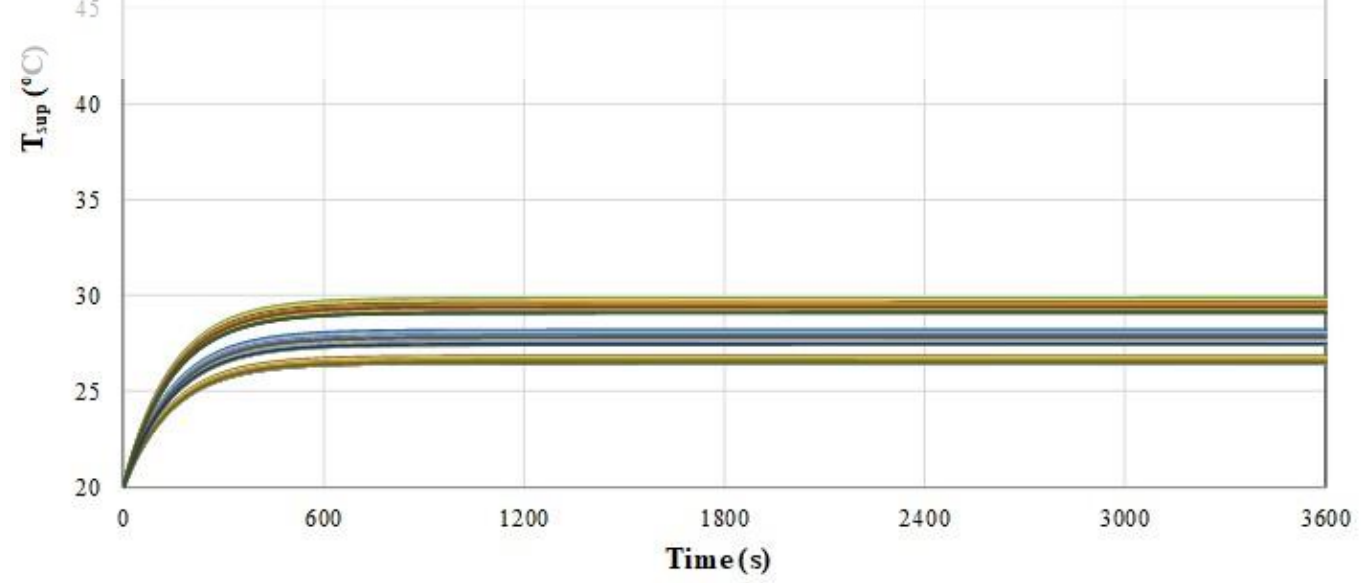

Figure 7: Evolution of the surface temperature of the leaves (elements 7244-7333) of the branch 111, located on level 4, facing towards the fire front 
The values of the view factors obtained show that its maximum value is reached in the main trunk (element 1) and that its minimum value is reached in the branch, element 124, located at the top of the pine tree (level 4) in the opposite area to that of the fire front, that is, in the most protected area of the pine tree. With regard to leaves, the values of the view factors decrease from level 1 to level 4, that is, from the bottom to the top of the maritime pine tree. By level, the highest values are obtained on the leaves that are in the area of the pine tree facing the fire front and the lowest values are obtained on the leaves that are in the area of the pine tree opposite the fire front.

The surface temperature of the leaves decreases from level 1 to level 4 . The surface temperature of the leaves varies between $35.7^{\circ}$ and $49.7^{\circ} \mathrm{C}$ in level 1 , between $30.6^{\circ}$ and $39.0^{\circ} \mathrm{C}$ in level 2 , between $28.3^{\circ}$ and $33.2^{\circ} \mathrm{C}$ in level 3, and between $26.5^{\circ}$ and $29.6^{\circ} \mathrm{C}$ in level 4 . It is noted that the distribution of surface temperatures is more uniform in the leaves of the branches at the top of the pine tree than in the leaves of the branches closest to the ground. By level, the surface temperature of the leaves located at the front of the branch are lower than those located at the rear. In each Figure, this is evidenced by the grouping of the surface temperatures of the leaves according to two or three sets of values. For example, the distribution of the surface temperatures of the leaves of level 2 can be defined according to three sets of values: one, between $30.1^{\circ}$ and $31.3^{\circ} \mathrm{C}$; two, between $32.6^{\circ}$ and $34.1^{\circ} \mathrm{C}$; and three, between $36.2^{\circ}$ and $39.0^{\circ} \mathrm{C}$.

The surface temperature of the leaves settles after about $900 \mathrm{~s}$ for level 1, about $800 \mathrm{~s}$ for level 2, about $700 \mathrm{~s}$ for level 3 and about $600 \mathrm{~s}$ for level 4. The results show that surface temperatures stabilize more quickly on leaves located on the branches at the top of the tree than those located on branch

In general, the result present a different ther tree. The most affected as it is expected given the height of the fire fro
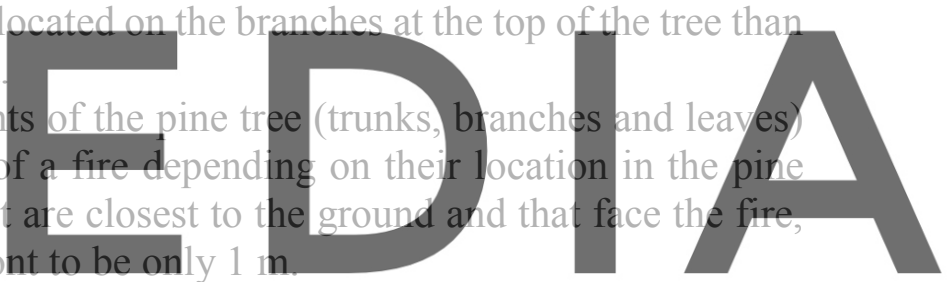

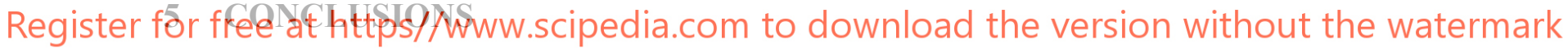

In this work, the numerical model of the maritime pine tree thermal behaviour was developed from a grid generation geometry and energy balance integral equations that represent the heat transfer processes. It was applied in a situation where the pine tree is subject to the effect of a fire front with a height of $1 \mathrm{~m}$ and a flame temperature of $500^{\circ} \mathrm{C}$. The trunks, branches and leaves of the pine are represented by 8863 cylindrical elements and are arranged over four levels. The results of the numerical simulation were the view factors and the transient evolution of the surface temperature of the maritime pine tree elements.

The main conclusions are that the values of the form factors of the elements decrease from level 1 (lower zone) to level 4 (upper zone) of the pine tree. The surface temperature of the leaves decreases as the level of the pine tree rises. The distribution of surface temperature also becomes more uniform as the level of the pine tree rises. The stabilization of the surface temperature occurs in less time at the upper levels than at the lower levels. The leaves located in front of the branch (towards the fire front) have the highest values of surface temperature. Thus, it is noted that the thermal behaviour of the pine tree is not uniform and that it is possible to identify which areas are most affected in the presence of a forest fire. 


\section{ACKNOWLEDGMENT}

The authors would like to acknowledge the support of the project reference PCIF/MPG/0108/2017, funded by the Portuguese Foundation of Science and Technology (FCT).

\section{REFERENCES}

[1] ICNF - Instituto de Conservação da Natureza e das Florestas. $6^{\circ}$ Inventário Florestal Nacional (IFN6). Available online: http://www2.icnf.pt/portal/florestas/ifn/ifn6 (accessed on 13 December 2020).

[2] Conceição, E., Silva, M., André, J. and Viegas, D. Thermal behaviour simulation of the passenger compartment of vehicles. Int. J. Veh. Des. (2000) 24(4):372-387.

[3] Conceição, E. and Lúcio, M. Numerical simulation of passive and active solar strategies in building with complex tonology. Build. Simul. (2010) 3:245-261.

[4] Conceição, E. Evaluation of thermal comfort and local discomfort conditions using the numerical modelling of the human and clothing thermal system. In: Proceedings of the $7^{\text {th }}$ International Conference on Air Distribution in Rooms, Room Vent 2000, Reading, UK, 912 July 2000.

[5] Conceição, E. and Lúcio, M. Numerical study of thermal response of school buildings in summer conditions," In: Proceedings of the $8^{\text {th }}$ International Conference and Exhibition on Healthy Buildings, HB 2006, Lisbon, Portugal, 4-8 June 2006.

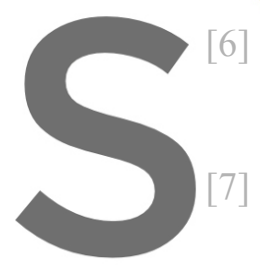
Conceição, E. and Lúcio, M. Numerical
sensation. In: Proceedings of the $6^{\text {th }}$ Portu
Faro, Portugal, 11-12 Jund 2001.
Conceição, E. and Lício, M. Evaluation of
system placed in front and behind two stud
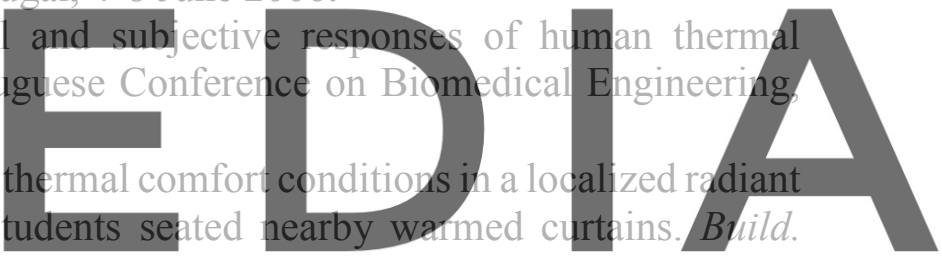
Environ. (2010), 45:2100-2110.

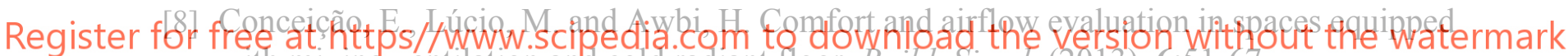
With mixing ventilation and cold radiant floor. Build. Simul. (2013), 6:51-67.

[9] Conceição, E. and Lúcio, M. Numerical simulation of the application of solar radiant systems, internal airflow and occupants' presence in the improvement of comfort in winter conditions. Buildings (2016) 6(3):38.

[10] Conceição, E., Lúcio, M. and Lopes, M. Application of an indoor greenhouse in the energy and thermal comfort performance in a kindergarten school building in the south of Portugal in winter conditions. WSEAS Trans. Environ. Dev. (2008) 4: 644-654.

[11] Conceição, E., Lúcio, M., Ruano, A. and Crispim, E. Development of a temperature control model used in HVAC systems in school spaces in Mediterranean climate. Build. Environ. (2009) 44:871-877.

[12] Conceição, E., Nunes, A., Gomes, J. and Lúcio, M. Application of a school building thermal response numerical model in the evolution of the adaptive thermal comfort level in the Mediterranean environment. Int. J. Vent. (2010) 9:287-304.

[13] Conceição, E., Gomes, J. and Ruano, A. Application of HVAC systems with control based on PMV index in university buildings with complex topology. IFAC PapersOnLine (2018) 51(10):20-25.

[14] Conceição, E. and Lúcio, M. Numerical study of the thermal efficiency of a school building 
with complex topology for different orientations. Indoor Built Environ. (2009) 18:41-51.

[15] Conceição, E. and Lúcio, M. Evolution of thermal comfort conditions in a classroom equipped with radiant cooling systems and subjected to uniform convective environment. Appl. Math. Model. (2011) 35(3):1292-1305.

[16] Conceição, E. and Lúcio, M. Numerical study of the influence of opaque external trees with pyramidal shape on the thermal behaviour of a school building in summer conditions. Indoor Built Environ. (2010) 19(6):657-667.

[17] Conceição, E., Lúcio, M. and Farinho, J. Experimental and numerical study of personalized of ventilation in classrooms desks. In: Proceedings of the $10^{\text {th }}$ International Conference on Air Distribution in Rooms, Helsinki, Finland, 13-15 June 2007.

[18] Conceição, E., Rosa, S., Custódio, A., Andrade, R., Meira, M. and Lúcio, M. Study of airflow around occupants seated in desks equipped with upper and lower air terminal devices for slightly warm environments. HVAC\&R Res. (2010) 16(4):401-412.
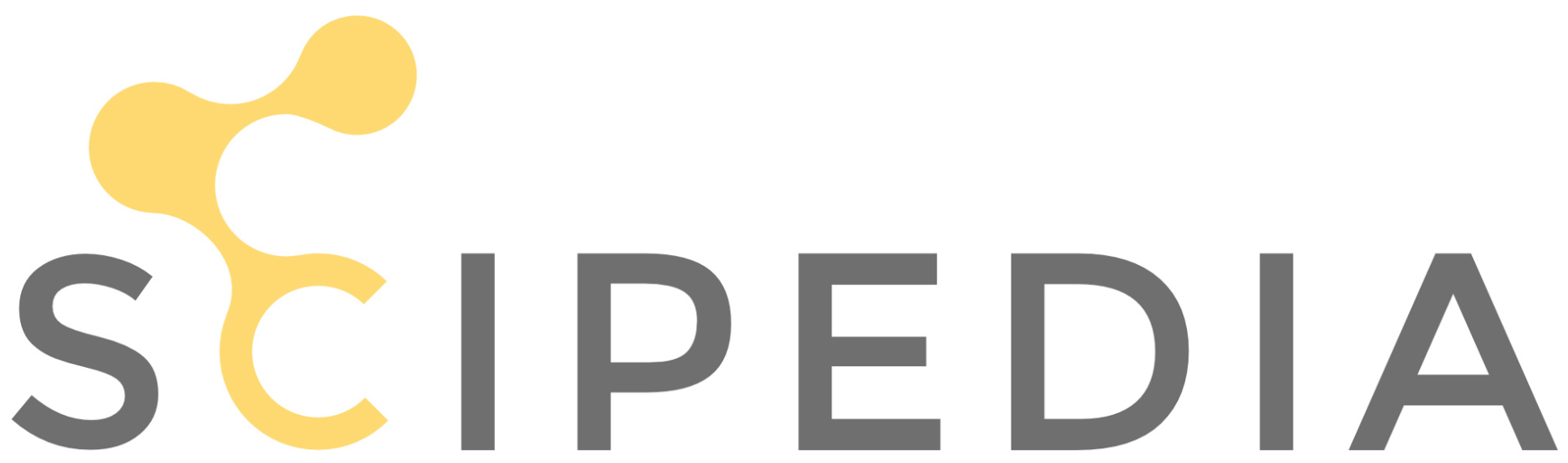